\title{
Luminescence and scintillation properties of the small band gap compound $\mathrm{LaI}_{3}: \mathrm{Ce}^{3+}$
}

\author{
A. Bessiere ${ }^{\mathrm{a}}$, P. Dorenbos ${ }^{\mathrm{a}, *}$, C.W.E. van Eijk ${ }^{\mathrm{a}}$, K.W. Krämer ${ }^{\mathrm{b}}$, H.U. Güdel ${ }^{\mathrm{b}}$ \\ C. de Mello Donega ${ }^{\mathrm{c}}$, A. Meijerink ${ }^{\mathrm{c}}$ \\ ${ }^{a}$ Radiation Technology Group, Interfaculty Reactor Institute, Delft University of Technology, Mekelweg 15, 2629 JB Delft, \\ The Netherlands \\ ${ }^{\mathrm{b}}$ Department of Chemistry and Biochemistry, University of Bern, Freiestrasse 3, 3000 Bern 9, Switzerland \\ ${ }^{\mathrm{c}}$ Chemistry of Condensed Matter, Debye Institute, University of Utrecht, P.O. Box 80.000, 3508 TA Utrecht, The Netherlands
}

Available online 21 August 2004

\begin{abstract}
$\mathrm{LaI}_{3}: \mathrm{Ce}^{3+}$ has the smallest band gap in the $\mathrm{LaX}_{3}: \mathrm{Ce}^{3+}(\mathrm{X}=\mathrm{F}, \mathrm{Cl}, \mathrm{Br}, \mathrm{I})$ series and hence a potentially higher scintillation yield. The luminescence properties of $\mathrm{LaI}_{3}: \mathrm{Ce}$ were investigated by means of optical, X-ray, and $\gamma$-ray excitation. Unexpectedly, the compound is a poor scintillator at room temperature but presents good scintillation properties for temperatures below $100 \mathrm{~K}$ where $\mathrm{Ce}^{3+}$ emission is observed peaking at 452 and $502 \mathrm{~nm}$ with a yield of $\sim 16000$ photons/MeV. The drastic thermal quenching of luminescence is explained by the proximity of the $\mathrm{Ce}^{3+}$ lowest $5 \mathrm{~d}$ excited state to the host conduction band. Autoionization of $\mathrm{Ce}^{3+}$ therefore prevents any scintillation effect at room temperature. The positions of $\mathrm{Ce}^{3+}$ levels relative to the host bands were estimated.
\end{abstract}

(C) 2004 Elsevier B.V. All rights reserved.

PACS: 29.30.Hs; 29.40.Mc; 42.70.-a

Keywords: Iodide; $\mathrm{Ce} 3+; \gamma$-detection; Rare-earth trihalides; Scintillation crystals

\section{Introduction}

In the past five years the scintillation properties of the rare earth trihalides $\mathrm{LnX}_{3}: \mathrm{Ce}^{3+}$ were studied. First $\mathrm{LaF}_{3}: \mathrm{Ce}^{3+}$ demonstrated poor

\footnotetext{
*Corresponding author. Tel.: + 31-15-2781336; fax: + 31-152786422.

E-mail address: dorenbos@iri.tudelft.nl (P. Dorenbos).
}

scintillation properties, i.e. a light yield of 2200 photons/ $\mathrm{MeV}$, a decay time of $26.5 \mathrm{~ns}$ and a density of $5.9 \mathrm{~g} / \mathrm{cm}^{3}[1,2]$. The low value for the scintillation yield was attributed to a too large energy gap between the lowest $\mathrm{Ce}^{3+}$ 4f level and the top of the host valence band $[3,4]$. The trapping of holes from the host valence band by $\mathrm{Ce}^{3+}$ is then a slow process. Instead Self-Trapped Excitons (STE) are created that quench thermally 
at room temperature. $\mathrm{LaCl}_{3}: \mathrm{Ce}^{3+}[5-7]$ and next $\mathrm{LaBr}_{3}: \mathrm{Ce}^{3+}[8,9]$ showed much more favorable features. They both combine a high light yield (respectively, 49000 and 61000 photons/MeV) with excellent energy resolution (around 3\% for the $662 \mathrm{keV}$ peak) and fast luminescence decay (respectively, $26 \mathrm{~ns}$ and $17-35 \mathrm{~ns}$ ). They are the first choice candidates for scintillation crystals when good energy resolution and fast response are needed. We decided to look for improved performance based on the fact that the maximum attainable scintillation yield is directly proportional to the number of electron-holes pairs created when a $\gamma$ quantum is absorbed. The number of electron-hole pairs is inversely proportional to the band gap. In order to increase the scintillation light yield we aim to study smaller band gap materials. In the sequence $\mathrm{LaF}_{3}, \mathrm{LaCl}_{3}$, $\mathrm{LaBr}_{3}$ the gap decreases and light yield increases. The optical and scintillation properties of $\mathrm{Ce}$ doped lanthanum halide $\mathrm{LaI}_{3}$ : $\mathrm{Ce}$ with even smaller bandgap are the topic of this publication.

\section{Results}

$\mathrm{LaI}_{3}:$ Ce was grown as a single crystal using the vertical Bridgman technique [10]. $\mathrm{LaI}_{3}$ crystallizes in the $\mathrm{PuBr}_{3}$-type structure with space group $\mathrm{Cmcm}$ [11]. The density is $5.614 \mathrm{~g} / \mathrm{cm}^{3}$. As $\mathrm{LaI}_{3}: \mathrm{Ce}$ is hygroscopic most experiments were performed on samples sealed in quartz ampoules.

$\mathrm{X}$-ray excited optical luminescence spectra of $\mathrm{LaI}_{3}: 0.5 \% \mathrm{Ce}^{3+}$ were recorded at different temperatures between 85 and $350 \mathrm{~K}$ (see Fig. 1). At $85 \mathrm{~K}$ the spectrum is dominated by two very intense emission bands peaking at 452 and $502 \mathrm{~nm}$ assigned to $\mathrm{Ce}^{3+} 5 \mathrm{~d}-4 \mathrm{f}$ transitions. The two $\mathrm{Ce}^{3+}$ transitions from the lowest $5 \mathrm{~d}$ excited state to the ${ }^{2} \mathrm{~F}_{5 / 2}$ and ${ }^{2} \mathrm{~F}_{7 / 2}$ ground state levels are perfectly resolved. The spin-orbit splitting of the ${ }^{2} \mathrm{~F}$ ground state of $\mathrm{Ce}^{3+}$ is $\sim 2000 \mathrm{~cm}^{-1}$. In addition a broad and low-intensity band can be distinguished between 560 and $660 \mathrm{~nm}$. It is only visible from $85 \mathrm{~K}$ up to $\sim 150 \mathrm{~K}$ and is attributed to STE luminescence. In contrast to $\mathrm{LaCl}_{3}: \mathrm{Ce}^{3+}$ [12] no STE emission was observed on the short wavelength side of the $\mathrm{Ce}^{3+}$ emission.

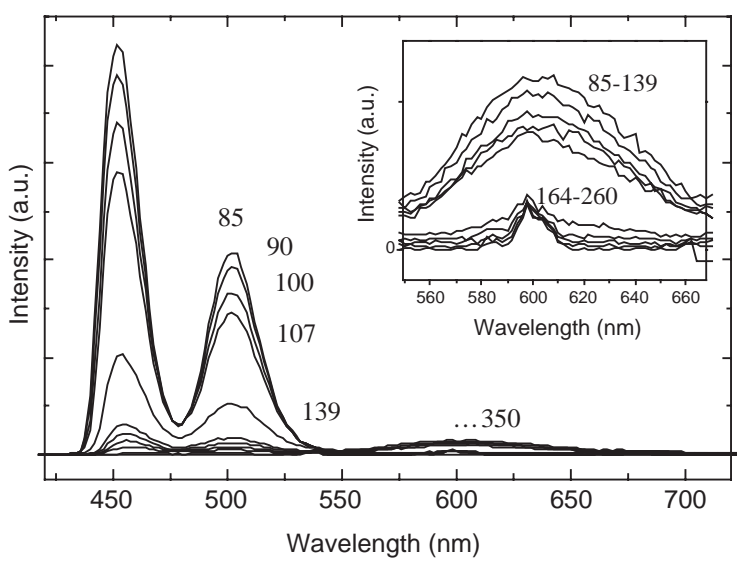

Fig. 1. X-ray induced emission spectra of $\mathrm{LaI}_{3}: 0.5 \% \mathrm{Ce}$ recorded at temperatures between 85 and $350 \mathrm{~K}$.

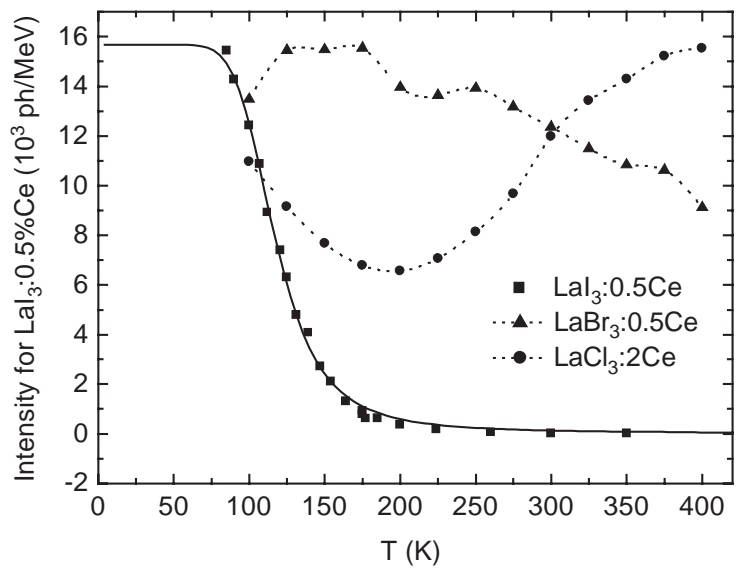

Fig. 2. Photon yields under $\mathrm{X}$-ray excitation as a function of temperature for the $\mathrm{LaX}_{3}: \mathrm{Ce}(\mathrm{X}=\mathrm{Cl}, \mathrm{Br}, \mathrm{I})$ compounds. Data for $\mathrm{LaCl}_{3}: \mathrm{Ce}$ and $\mathrm{LaBr}_{3}: \mathrm{Ce}$ were respectively taken from [9] and [12].

As the temperature increases the intensity of the $\mathrm{Ce}^{3+}$ doublet emission dramatically drops. At $350 \mathrm{~K}$ the $\mathrm{Ce}^{3+}$ emission bands are just above the noise level. The absolute light yields of $\mathrm{Ce}^{3+}$ emission for the different temperatures were evaluated by comparison to $\mathrm{YAlO}_{3}: \mathrm{Ce}$ emission under the same conditions. The evolution of the $\mathrm{Ce}^{3+}$ light yield as a function of temperature $(T)$ is drawn in Fig. 2. For comparison the evolution of the light yields of $\mathrm{LaBr}_{3}: 0.5 \% \mathrm{Ce}$ and $\mathrm{LaCl}_{3}: 2 \% \mathrm{Ce}$ 
are shown as well in Fig. 2 as dotted lines. For $\mathrm{LaCl}_{3}: 2 \% \mathrm{Ce}$ the non monotonous trend exhibited was interpreted as a correlation between 100 and $225 \mathrm{~K}$ and then as an anti-correlation between 225 and $400 \mathrm{~K}$ with the STE emission intensity in the material [5,12]. A Ce emission mechanism by trapping part of the STEs by $\mathrm{Ce}^{3+}$ was therefore proposed. For $\mathrm{LaBr}_{3}: 0.5 \% \mathrm{Ce}$ the light yield decreases with temperature again correlating with the STE emission on the pure compound [9]. $\mathrm{LaI}_{3}: \mathrm{Ce}$ exhibits a completely different $T$ dependence than the other two materials Which is interpreted as a typical quenching behavior.

The solid curve through the $\mathrm{LaI}_{3}: \mathrm{Ce}$ data represent a model calculation used to describe thermal quenching of luminescence. The light yield of the luminescence is given by

$I(T)=\frac{I_{0}}{1+\Gamma_{0} / \Gamma v \exp \left(-\Delta E_{q} / k T\right)}$

where $I(T)$ is the light yield at temperature $T, I_{0}$ the light yield at $T=0, \Gamma_{0}$ and $\Gamma_{v}$ respectively, the thermal quenching rate at $T=\infty$ and the radiative transition rate. $\Delta E_{\mathrm{q}}$ is the activation energy for thermal quenching and $k$ the Boltzmann constant. From a fit to Eq. (1) values of $I_{0}=15700 \pm 300 \mathrm{ph} / \mathrm{MeV} \Gamma_{0} / \Gamma_{v}=2500 \pm 700$ and $\Delta E_{\mathrm{q}}=79 \pm 4 \mathrm{meV}$ are obtained.

The absorption spectrum recorded at $6 \mathrm{~K}$ is shown in Fig. 3 together with the optical excitation spectrum of $\mathrm{Ce}^{3+}$ emission at $500 \mathrm{~nm}$ recorded at

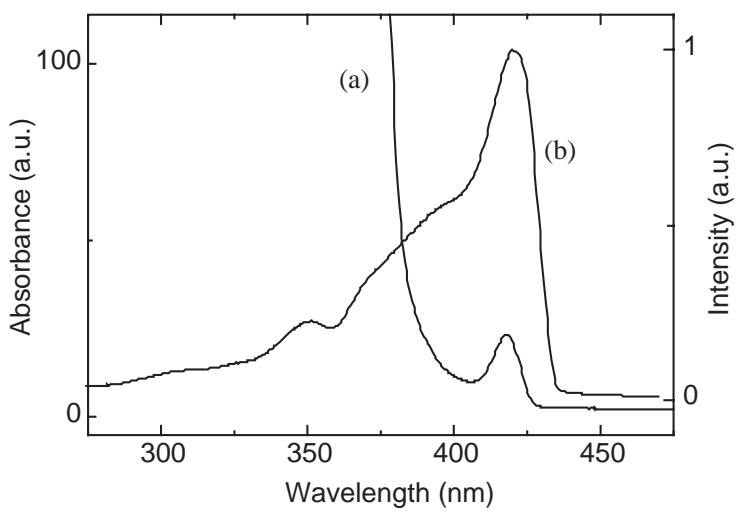

Fig. 3. (a) Absorption spectrum recorded at $6 \mathrm{~K}$ and (b) optical excitation spectrum monitoring emission at $500 \mathrm{~nm}$ recorded at $4 \mathrm{~K}$ for $\mathrm{LaI}_{3}: 0.5 \% \mathrm{Ce}$.
$4 \mathrm{~K}$. The absorption spectrum consists of a weak peak at $\sim 420 \mathrm{~nm}$ attributed to the $\mathrm{Ce}^{3+} 4 \mathrm{f}-5 \mathrm{~d}$ transitions and it increases steeply below $380 \mathrm{~nm}$. The optical band gap is estimated to be $3.3 \mathrm{eV}$ $(376 \mathrm{~nm})$ at $6 \mathrm{~K}$. The excitation spectrum monitoring the $500 \mathrm{~nm}$ emission is composed of an intense band peaking at $423 \mathrm{~nm}(2.93 \mathrm{eV})$ assigned to $\mathrm{Ce}^{3+}$ $4 \mathrm{f}-5 \mathrm{~d}$ transitions and of a broad structured band spreading between $320(3.88 \mathrm{eV})$ and $415 \mathrm{~nm}$ $(2.99 \mathrm{eV})$.

Decay time measurements of $\mathrm{LaI}_{3}: 0.5 \% \mathrm{Ce}$ from 10 to $185 \mathrm{~K}$ under $406 \mathrm{~nm}(3.05 \mathrm{eV})$ laser excitation were recorded. Decay curves for three temperatures are shown in the inset of Fig. 4. All curves are composed of a single exponential component. The decay time $\tau$ of the $\mathrm{Ce}^{3+}$ luminescence is reported as a function of $T$ in Fig. 4 . For $T<125 \mathrm{~K}$ the characteristic decay time is $\sim 19 \mathrm{~ns}$ which is typical for the allowed $5 \mathrm{~d}-4 \mathrm{f} \mathrm{Ce}^{3+}$ transitions. It remains stable from $10 \mathrm{~K}$ to $125 \mathrm{~K}$ and then drops.

The solid curve in Fig. 4 shows model calculations according to the quenching process:

$\tau(T)=\frac{1 / \Gamma_{v}}{1+\Gamma_{0} / \Gamma_{v} \exp \left(-\Delta E_{q} / k T\right)}$

where $\Gamma_{0}, \Gamma_{v}$ and $\Delta E_{\mathrm{q}}$ have the same meaning as in Eq. (1). From a fit to Eq. (2) values of $1 / \Gamma_{v}=18.9 \pm 0.3 \mathrm{~ns}$ and $\Delta E_{\mathrm{q}}=200 \pm 20$ meV were calculated. Different values of

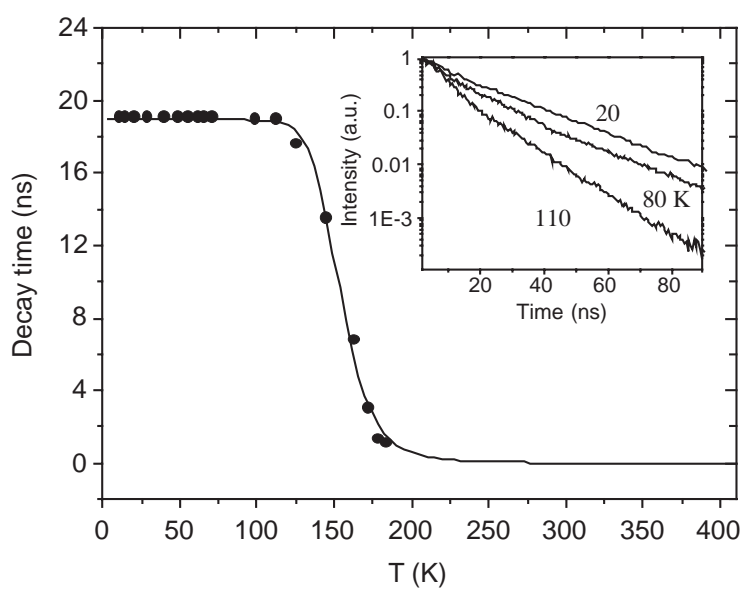

Fig. 4. Decay times of $\mathrm{LaI}_{3}: 0.5 \% \mathrm{Ce}$ as a function of temperature. The solid line is a fitting following Eq. (2). Inset: decay curves at three different temperatures. 
$\Gamma_{0}=1.3 \times 10^{11} \pm 0.4 \times 10^{11} \mathrm{~Hz}$ or $\Gamma_{0}=1.6 \times 10^{14}$ $\pm 0.2 \times 10^{14} \mathrm{~Hz}$ can be deduced from the values of $\Gamma_{0} / \Gamma_{v}$ found resp. in Eq. (1) or Eq. (2).

\section{Discussion and conclusions}

The scintillation properties of $\mathrm{LaI}_{3}: \mathrm{Ce}$ are peculiar. At $T<70 \mathrm{~K}$ the scintillation output consists of an intense $(\sim 16000 \mathrm{ph} / \mathrm{MeV})$ doublet emission arising from the $\mathrm{Ce}^{3+} 5 \mathrm{~d}-4 \mathrm{f}$ transition. Furthermore, it seems that luminescence is produced solely by a fast process ( $\sim 20 \mathrm{~ns})$ showing no evidence of STE intervention. However these interesting scintillation properties totally collapse as the temperature rises. At $200 \mathrm{~K}$ the light yield amounts only to some hundred of photons/MeV and the lifetime of the $\mathrm{Ce}^{3+}$ luminescence is around $1-2$ ns. Experiments monitoring the light yield and the decay time under X-ray or optical excitation showed thermal quenching behavior for the $\mathrm{Ce}^{3+}$ luminescence. Considering that $\mathrm{LaI}_{3}$ was initially chosen as the ultimate host in the $\mathrm{LaX}_{3}$ series due to its smallest band gap we propose an explanation of the quenching based on the position of the $\mathrm{Ce}^{3+}$ levels relative to the host bands, see Fig. 5. At low temperature the lowest $\mathrm{Ce}^{3+} 5 \mathrm{~d}$ level is below the conduction band and enables a fast transfer of free electrons and holes to $\mathrm{Ce}^{3+}$. The material then presents fast and efficient scintillation properties. When the temperature increases thermal energy is provided to the electron of the $\mathrm{Ce}^{3+}$ excited configuration. As the $\mathrm{Ce}^{3+} 5 \mathrm{~d}$ level is close in energy to the

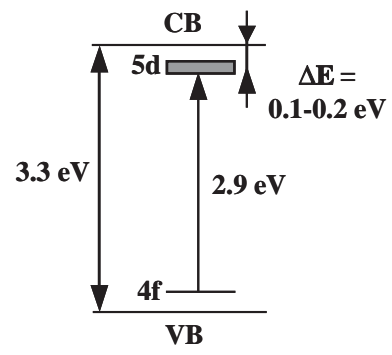

Fig. 5. Scheme of $\mathrm{Ce}^{3+} 4 \mathrm{f}$ and lowest $5 \mathrm{~d}$ levels positions relative to the host bands in $\mathrm{LaI}_{3}: \mathrm{Ce}$. VB : valence band. CB: conduction band. conduction band the electron can escape into the conduction band of the host. A non-radiative process may occur and scintillation light is lost. In this interpretation the activation energies calculated above may be closely related to the energy difference $\Delta E$ between the host conduction band and the $\mathrm{Ce}^{3+}$ excited state [13]. Two slightly different values were found for the activation energies depending on the set-up used for the experiment (light yield under X-ray excitation or decay time under laser excitation). The difference may arise from a temperature offset between the two types of temperature control devices. It is not possible to reduce the uncertainty on that point. Thus considering the picture described in Fig. 5 the lowest $5 \mathrm{~d}$ state of $\mathrm{Ce}^{3+}$ would be situated at $\sim 0.1-0.2 \mathrm{eV}$ from the bottom of the conduction band (see Fig. 5).

Photoconductivity measurements are envisaged to confirm this model. In any case $\mathrm{LaI}_{3}: \mathrm{Ce}$ demonstrated its failure as a scintillator due to a too small band gap compared with the energy difference between the $4 \mathrm{f}$ and $5 \mathrm{~d}$ Ce levels. One would expect to return to good scintillation properties with a slight increase of the bandgap. This is likely to be obtained with the replacement of the lanthanum by lutetium. Thus $\mathrm{LuI}_{3}: \mathrm{Ce}$ is currently under study to verify this hypothesis and test its scintillation properties.

\section{Acknowledgments}

These investigations have been supported by the Netherlands Technology Foundation (STW), the Swiss National Science Foundation and SaintGobain Cristaux et Detecteurs, France.

\section{References}

[1] W.W. Moses, S.E. Derenzo, Nucl. Instr. and Meth. A 299 (1990) 51.

[2] A.J. Wojtowicz, M. Balcerzyk, E. Berman, A. Lempicki, Phys. Rev. B 49 (21) (1994) 14880.

[3] D. Bouttet, C. Dujardin, C. Pedrini, W. Brunat, D. Tran Minh Duc, J.Y. Gesland, Proceedings of International Conference On Inorganic Scintillators and Their Applications, SCINT95 (1996) Delft University Press, 111. 
[4] C. Pedrini, A.N. Belsky, A.N. Vasilev, D. Bouttet, C. Dujardin, B. Moine, P. Martin, M.J. Weber, Mat. Res. Soc. Symp. Proc. 348 (1994) 225.

[5] O. Guillot-Noël, J.T.M. de Haas, P. Dorenbos, C.W.E. van Eijk, K. Krämer, H.U. Güdel, J. Lumin. 85 (1999) 21.

[6] E.V.D. van Loef, P. Dorenbos, C.W.E. van Eijk, K. Krämer, H.U. Güdel, Appl. Phys. Lett. 77 (10) (2000) 1467.

[7] E.V.D. van Loef, P. Dorenbos, C.W.E. van Eijk, K. Krämer, H.U. Güdel, IEEE Trans. Nucl. Sci. NS-48 (3) (2001) 341 .
[8] E.V.D. van Loef, P. Dorenbos, C.W.E. van Eijk, K. Krämer, H.U. Güdel, Appl. Phys. Lett. 79 (2001) 1573.

[9] E.V.D. van Loef, P. Dorenbos, C.W.E. van Eijk, K.W. Krämer, H.U. Güdel, Nucl. Instr. and Meth. A 486 (2002) 254.

[10] L.B. Asprey, T.K. Keenan, F.H. Kruse, Inor. Chem. 3 (1964) 1137.

[11] K.W. Kramer, H.U. Gudel, P. Fischer, L. Keller, Appl. Phys. A 74 (Suppl.) (2002) S595.

[12] E.V.D. van Loef, P. Dorenbos, C.W.E. van Eijk, J. Phys.: Condens. Mat 15 (2003) 1367.

[13] Li-Ji Lyu, D.S. Hamilton, J. Lumin. 48-49 (1991) 251. 